\title{
"No éramos del MIR los pobladores, nosotros estábamos por una necesidad que era la vivienda": Los pobladores del campamento Nueva La Habana y el MIR, 1970-1973
}

\author{
Alejandra Patricia Araya González ${ }^{1}$ \\ Recibido: 20 de marzo de 2017 - Aceptado: 14 de mayo de 2017
}

\begin{abstract}
Resumen
Dentro de los repertorios de acción del movimiento de pobladores, sobresalen las formas en que estos actores urbanos se relacionaron con organismos políticos durante la búsqueda de solución a su problema habitacional. Este artículo propone un análisis de las relaciones socio-políticas que sostuvieron los pobladores del Nueva La Habana con el MIR entre 1970-1973, postulando que aquellos vínculos marcaron una dinámica social-política oscilante entre la búsqueda de una asistencia habitacional y la influencia política de un movimiento revolucionario que recién se vinculaba con los pobladores. En esta línea, se postula que la construcción identitaria de los pobladores de Nueva La Habana se puede entender a partir de una conducta pragmática en la experiencia política que vivieron con los dirigentes del MIR, constituyendo un sello identitario sustancial, que abre una perspectiva histórica para comprender la conducta social-política de los pobladores durante la segunda mitad del siglo XX y el Chile actual.
\end{abstract}

Palabras clave: Movimiento de pobladores, Campamento Nueva La Habana, MIR, experiencia política.

"We, the squatters, did not belong to the MIR - we were there because our necessity of dwelling": Squatters of the squatter settlement Nueva La Habana and the MIR, 1970-1973

Abstract

In histories of action of the squatters' movement, we can highlight the ways in which these urban actors related to political organisms looking for a solution to their housing problem. This article proposes an analysis of the

1 Chilena. Magíster en Historia, Universidad Andrés Bello. Ayudante de cátedra en Universidad Andrés Bello y Universidad Adolfo Ibáñez. E-mail: alejandra.araya21@gmail.com 
socio-political relations among the squatters of New Havana and the MIR between 1970-1973, postulating that those links marked an oscillating social-political dynamics between the search for a housing assistance and the political influence of a revolutionary movement that was linked with the squatters. In this sense, it is postulated that the identity construction of the inhabitants of Nueva La Habana can be understood from a pragmatic behavior in the political experience they lived with MIR's leaders, constituting a substantial identity character that opens a historical perspective for understanding the social-political behavior of the squatters during the second half of the Twentieth Century and today in Chile.

Keywords: Movement of squatters, New Havana squatter settlement, MIR, political experience.

\section{"Os povoadores não éramos do MIR, nós estávamos por uma necessidade que foi a morada": 0s moradores do acampamento a Nueva La Habana e o MIR, 1970-1973 \\ Resumo}

Dentro dos repertórios de ação do movimento de povoadores, sobressaem as maneiras pelas quais esses atores urbanos se relacionaram com organizações políticas durante a busca de uma solução para seu problema habitacional. Este artigo propõe uma análise das relações sócio-políticas que sustentaram aos povoadores da Nueva La Habana com o MIR entre 1970-1973, postulando que esses laços, marcaram uma dinâmica sócio-política que oscilam entre a busca de assistência habitacional e a influência política de um movimento revolucionário que, recentemente, se vinculava com os povoadores. Nesta linha, postula-se que a construção da identidade dos povoadores da Nueva La Habana pode ser entendida a partir de uma conduta pragmática na experiência política viveram com os dirigentes do MIR, constituindo um selo de identidade substancial, que abre uma perspectiva histórica para compreender a conduta sócio-política dos povoadores durante a segunda metade do século XX e o Chile atual.

Palavras-chave: Movimento de povoadores, Acampamento Nova Havana, MIR, experiência política.

Los pobladores de Santiago se han constituido como sujetos históricos de gran relevancia en el escenario urbano desde la segunda mitad del siglo $X X$. Ellos fueron vistos como precursores de una nueva forma de protesta, que se manifestó en la toma de sitios, cuya mayor coyuntura fue la toma de la ex chacra La Feria, o "toma de la Victoria" en 1957. ' La ocupación de

2 Respecto a la toma de la ex chacra La Feria, acto que dio origen a la construcción de la población La Victoria, se recomienda revisar Alexis Cortés, "El relato identitario y la toma de 
terrenos se concibió como una forma de habitar en la ciudad, dado el déficit de viviendas que afectaba a los "sin casa" y, primordialmente, se afianzó como una acción para conseguir la negociación habitacional con autoridades estatales, la Iglesia o los organismos políticos.

La falta de viviendas y la exponencial ocupación de sitios, marcaron una nueva lógica urbana enraizada en el problema habitacional. Como plantea Mario Garcés y otros autores, los pobladores inauguraron una conducta urbana que influyó en la configuración de distintas ciudades del país y los instaló como nuevos sujetos transformadores del espacio urbano (Garcés, 2014; Espinoza, 1988; Hidalgo, 2005). El aumento exponencial de las tomas de sitios tras el ejemplo de lucha efectiva que significó La Victoria, demostró que este mecanismo ilegal era la salida al problema habitacional que las autoridades estatales no lograron remediar. En este sentido, para los años sesenta, los pobladores se habían convertido en verdaderos propietarios de viviendas (homeowners), modificando los cánones de propiedad habitacional que se habían dado hasta mediados del siglo XX, y estableciendo una forma de propiedad dominante, productiva y valiente: la toma de sitios, que actuaba como un campo de fuerza con gran capacidad de expansión (Murphy, 2015).

Una vez tomado el terreno, se procedía a conformar un campamento levantado por carpas armadas con frazadas, sábanas o desechos. Los problemas que enfrentaron los pobladores no sólo fueron la falta de vivienda o de un terreno donde vivir, sino resolver la asistencia de servicios urbanos básicos como el agua potable, red de alcantarillado y electricidad. Solventar aquellos problemas significó buscar alternativas organizativas, y una de ellas fue estrechar vínculos con organismos políticos y sus dirigentes para gestionar asistencia. Armando De Ramón, Manuel Castells y otros autores postularon que desde mediados del siglo XX la intensificación de las tomas ilegales de terreno aumentaban de manera simultánea tanto el "poblamiento informal" como la influencia de organismos políticos en los campamentos (De Ramón, 1990; Alvarado et al., 1973; Castells, 1973; Santa María, 1973). En este contexto, se enmarca el análisis de las relaciones socio-políticas que sostuvieron los pobladores del campamento Nueva La Habana y los dirigentes del MIR entre 1970 y 1973.

terrenos de la población La Victoria", Centro de Investigación Social un Techo para Chile, Revista CIS. Vol. 10 (segundo semestre), 2007, pp. 86-92, "El movimiento de pobladores chilenos y la población La Victoria: ejemplaridad, movimientos sociales y el derecho a la ciudad", EURE, Santiago. Vol. 40, №119, 2014. Alexis Cortés y Julio Reyes (ed.), Memorias de la Victoria: relatos de vida en torno a los inicios de la población, Identidad Grupo de Memoria Popular, Editorial Quimantú, Santiago, 2007. 


\section{Las relaciones entre los pobladores y el MIR durante la coyuntura eleccionaria de 1970}

La influencia política del MIR en el movimiento de pobladores se inició con la reestructuración orgánica de 1967, la que promovió un acercamiento a las masas de la sociedad chilena. Dentro de los primeros grupos que influyeron, estuvieron los obreros, trabajadores y estudiantes, posteriormente se crearon alianzas con los pobladores. Para el MIR, el problema de la vivienda tenía su origen en el funcionamiento del sistema capitalista, puesto que éste, al promover la desigualdad socio-económica, no permitía el acceso a la vivienda en todas las capas de la sociedad, por lo que este derecho debía reivindicarse mediante la vía al socialismo, un sistema que concebían más igualitario. ${ }^{3}$ De esta manera, el MIR asoció la reivindicación habitacional con la lucha de clases que ellos mismos promovían y vinculó a los pobladores en su política revolucionaria. ${ }^{4}$ Al respecto, Garcés afirma que "para el MIR, los pobladores debían ganar en autonomía y generar nuevas formas de 'poder popular'" (2015: 43).

Sin embargo, las demandas habitacionales se intensificaron una vez que se creó el Ministerio de Vivienda y Urbanismo en 1965 y, más aún en los años posteriores, cuando se aproximaba una coyuntura electoral que llevaría

3 La creciente promoción de las tomas de sitios influidas por el MIR, fue efecto de una reorganización de bases y repertorios de acción que iniciaron los dirigentes del Movimiento en junio de 1967, bajo una nueva orientación liderada por la generación "no tradicional" del MIR. Desde sus inicios, en 1965, el MIR agrupó a diversos dirigentes políticos tradicionales que pretendieron desvincularse de las izquierdas institucionales, y crear un movimiento rupturista. Dentro de su orgánica coexistieron distintas líneas ideológicas, entre ellas, trotskistas, comunistas, maoístas y socialistas, que mantuvieron divisiones internas, complejizando los niveles de cohesión. La "joven generación" se distinguió de la "vieja generación" por ser un grupo de jóvenes desvinculados de las Juventudes Comunistas y Socialistas en los años sesenta. Entre 1967 y 1974, el MIR fue dirigido por Miguel Enríquez, uno de los jóvenes de esta nueva generación que redefinió las líneas teóricas y estratégicas del movimiento revolucionario, impulsando la acción directa y la influencia política en las masas sociales, es decir, en trabajadores, estudiantes y pobladores. Ver al respecto, Eugenia Palieraki, iLa revolución ya viene! El MIR chileno en los años sesenta, LOM, Santiago, 2014.

4 En su Declaración de Principios expusieron que "Las directivas burocráticas de los partidos tradicionales de la izquierda chilena defraudan las esperanzas de los trabajadores; en vez de luchar por el derrocamiento de la burguesía, se limitan a plantear reformas al régimen capitalista, en el terreno de la colaboración de clases, engañan a los trabajadores con una danza electoral permanente, olvidando la acción directa y la tradición revolucionaria del proletariado chileno. Incluso, sostienen que se puede alcanzar el socialismo por la "vía pacífica y parlamentaria", como si alguna vez en la historia de las clases dominantes hubieran entregado voluntariamente el poder". El MIR rechaza la teoría de la "vía pacífica" porque desarma políticamente al proletariado y por resultar inaplicable, ya que la propia burguesía es la que resistirá, incluso con la dictadura totalitaria y la guerra civil, antes de entregar pacíficamente el poder. Reafirmamos el principio marxista-leninista de que el único camino para derrocar al régimen capitalista es la insurrección armada", septiembre, 1965. En http:// chilemir.tripod.com/principios.html Revisado el 15-II-2016. 
a la presidencia a Salvador Allende con un proyecto nacional enfocado en el bienestar de los sectores populares. Ese escenario de algún modo facilitó las tomas de terreno y alianzas entre dirigentes de partidos o movimientos políticos y pobladores. En este contexto y, aunque las políticas del gobierno de Allende estuvieron marcadas por una ideología socialista, las demandas al gobierno y las tomas protagonizadas por los pobladores, formaron también parte de la Unidad Popular. Como propone Garcés,

"entre los años 1967-1973, los pobladores ampliaron y extendieron sus capacidades y estructuras organizativas -a través de Comités de Sin Casa, pero también Centros de Madres, y Juntas de Vecinos-; incrementaron sus movilizaciones y repertorios de acción, especialmente las 'tomas de sitios'" (2015: 34).

Por otra parte, el contacto entre pobladores y dirigentes políticos fue estimulado previamente, pues las campañas electorales de 1970 ampliaron y profundizaron los métodos de cooptación. En este contexto, el problema de la vivienda se situó como una demanda reivindicativa legítima, dado su carácter no revolucionario, puesto que la vivienda propia es un componente esencial dentro de la defensa de la propiedad privada, representando un incentivo de bienestar y status social, que ha generado una promoción histórica del "sueño de la casa propia", fuertemente impulsado por la institucionalidad. Así, las tomas de terreno se intensificaron gradualmente y muchas de ellas fueron promovidas por organismos políticos, tal como lo demuestra Castells en un estudio de la época:

"a partir del momento en que se concluyó el acuerdo de Unidad Popular (enero 1970), se aceleró el proceso de tomas, y el 11 de enero los partidos obreros, PC y PS, realizaron una gigantesca ocupación de terrenos en La Florida, Santiago, con anterioridad incluso al comienzo de las tomas del MIR en la capital" (1973: 25).

En este contexto, las tomas de sitios pasaron a ser escenarios cada vez más complejos, pues el gobierno y los partidos políticos las percibieron, por una parte, como movilizaciones legítimas y focos de cooptación, en una lógica de mecanismos de presión y negociación y, por otra, como fenómenos urbanos ilegales e incontrolables que debían ser reprimidos. Castells llamó a esta dialéctica "integración-represión", dentro de la que fueron representativas dos tomas de terreno a nivel nacional, y cuyos desenlaces se dieron con enfrentamientos armados, una de ellas en Concepción y otra en Puerto Montt. ${ }^{5}$ Ante los actos represivos desencadenados, las izquierdas instituciona-

5 Entre el 4 y 8 de marzo de 1969, 91 familias sin casa de Puerto Montt, apoyados por el ex diputado socialista Luis Espinoza, se tomaron un terreno eriazo ubicado en el sector de 
les y el MIR legitimaron su acción política. Los partidos políticos izquierdistas mantuvieron o aumentaron sus bases electorales, mientras el MIR amplió el movimiento de masas que decidió profundizar desde 1969, en el que integró a los pobladores. El número de tomas de terreno que habría orientado el MIR fue ascendente en el período: ocho en 1968, veintitrés en 1969, doscientas veinte en 1970 y ciento setenta y cinco en 1971 (El Rebelde, 1-XII-1971).

La nueva dirigencia del MIR tuvo que discutir necesariamente dos materias: una fue la decisión de seguir una vía pacífica o una vía armada para concretar la revolución y, la otra, apoyar o no la candidatura de Salvador Allende en la coyuntura eleccionaria. Ambas estaban estrechamente vinculadas, puesto que el debate giró en torno a tomar el poder por las armas, o por las urnas. En el documento "Elecciones, no; lucha armada único camino", redactado por Miguel Enríquez, el MIR llamó a las masas a no votar en las elecciones presidenciales, afirmando:

"es nocivo desarrollar actividad electoral, de la que nos abstendremos absoluta y categóricamente. Llamaremos a no votar: a la abstención electoral. No lo haremos ni a voto blanco, nulo o 'voto Che'; pues ellos se contabilizan como votos nulos o significan de hecho participar en el proceso. Nuestra actividad en este sentido será ilegal desde el momento en que está penado por la ley vigente no votar". 6

En esta línea y hasta ese entonces, el MIR no manifestó su apoyo a Salvador Allende. Incluso, en un documento publicado entre abril y mayo de 1970, se sostuvo: "Cualquiera que sea el desenlace electoral, estamos ciertos de que no se detendrá el avance de la revolución ni se hipotecará la necesidad de una estrategia revolucionara, sino que al contrario, se abrirá un nuevo periodo que con renovado vigor nos llevará hacia la revolución socialista en Chile" (Punto Final, 12-V-1970).

\footnotetext{
"Pampa Irigoin". Aunque fueron advertidos del desalojo, no abandonaron el lugar, y el 9 de marzo, se enfrentaron con carabineros armados en una batalla campal. En Concepción, se habría gestado un suceso similar, pero apoyado por miembros del PDC. De esta manera, surgió una controversia respecto a la acción represiva del gobierno de Frei Montalva, como también sobre las alianzas entre dirigentes democratacristianos y pobladores en la conducción de tomas de sitios. Además, la desaprobación por parte de las izquierdas hacia el gobierno, significó un golpe que deslegitimó rápidamente sus mecanismos de acción, sobre todo en relación al problema de la vivienda y los pobladores. Dos años después, el 8 de junio de 1971, bajo el gobierno de la UP, un comando de la Vanguardia Organizada del Pueblo (VOP), asesinó al ex Ministro del Interior de Frei Montalva, Edmundo Pérez Zujovic, en forma de ajusticiamiento por la masacre de Puerto Montt.

6 Ver documento "Posición del MIR: elecciones, no; lucha armada único camino", Documento interno MIR, 1969, p. 8.
} 
Sin embargo, durante julio del mismo año, el MIR llegó a un acuerdo con Allende en el que se pactó un alto a los atentados y a la actividad armada del movimiento, para no perjudicar la campaña electoral de aquel candidato socialista, pues frente a las movilizaciones izquierdistas, surgieron discursos que pretendieron invalidar la candidatura política de la UP (Punto Final, 21VII-1970).

En septiembre de 1970, con Allende electo en la votación popular, el MIR confirmó su apoyo a la UP, después de un reciente período de desaprobación y rechazo durante la campaña electoral. Esto evidenciaba las contradicciones y complejidades de las relaciones que tuvo el Movimiento con esta coalición política, que además, se prolongaron durante todo el gobierno de Allende. Así, el apoyo que dio el MIR a la UP no estuvo falto de tensiones, pues mantuvo desencuentros y, claramente, situaciones de pleno acuerdo, como el convenio entre la CORVI, el MIR y los pobladores para la instalación de estos últimos en terrenos que verían nacer el campamento Nueva La Habana en noviembre (Cofré, 2007: 88).

De esta manera, el MIR profundizó su influencia política en el movimiento de pobladores, intensificando alianzas que había forjado años antes. En este sentido, el acuerdo de instalación en el ex fundo Los Castaños de La Florida significó una situación coyuntural en el movimiento de masas que promovía el MIR. Tras el triunfo de Allende, el MIR publicó:

"Se ha obtenido una mayoría electoral de izquierda, que expresa la aspiración de las mayorías de ser gobierno. Se lucha para que la izquierda sea gobierno, o sea que los cargos públicos de Presidente, Ministros, etc., sean ocupados por la izquierda, pero hasta aquí desde el aparato represor del Estado capitalista hasta la explotación y la miseria en los campos y ciudades de Chile, permanecen intactos. LA META ES LA CONQUISTA DEL PODER POR LOS TRABAJADORES". ${ }^{7}$

Con una posición subversiva, el MIR advirtió la movilización de masas ante el desconocimiento y represión sobre aquellas, anunciando que "los obreros deben ocupar sus fábricas, los campesinos sus fundos, los pobladores a hacer barricadas en las calles" ${ }^{8}$. De esta advertencia, es posible constatar la conducta oscilante que manifestó el MIR durante el período, mostrando expresiones evidentes de apoyo a la UP y, al mismo tiempo, activando la movilización de masas para presionar al gobierno. Así, en octubre, el MIR declaró: "Sostenemos que el triunfo electoral de la izquierda, constituye un inmenso avance

7 Ver documento "El MIR y el triunfo de Salvador Allende", Declaración pública, septiembre de 1970, en Archivo Chile, CEME, p. 2.

8 Ibíd., p. 3. 
en la lucha del pueblo por conquistar el poder y objetivamente favorece el desarrollo de un camino revolucionario en Chile, y por tanto favorece también a la izquierda revolucionaria" (Punto Final, 13-X-1970).

Sin embargo, al mismo tiempo, el MIR participó activamente en colaboración con la UP, integrando miristas en la guardia personal de Salvador Allende, los Ilamados GAP (Grupo de Amigos Personales). Esta doble posición que ocupó el MIR se debió, probablemente, a que sus dirigentes vieron, por una parte, la oportunidad de acelerar el proceso revolucionario si se mantenían aliados a la UP, ya que ésta inició un gobierno socialista y les ofrecía un escenario favorable y, por otra, notaron que las masas populares movilizadas, les prestaban un amplio contingente de aliados, también para concretar la revolución socialista (Palieraki, 2014: 377).

Durante el gobierno de la UP, el MIR transitó entre encuentros y desencuentros en sus relaciones con los miembros del gobierno, sus propios militantes y sus simpatizantes, pues entre estos últimos existió un amplio apoyo hacia Salvador Allende que, incluso, se inició desde la campaña electoral.

Desde mediados de 1969 se inició una alianza entre pobladores y el MIR, cuando Víctor Toro, mirista, declaró públicamente su apoyo como dirigente a los pobladores de Santa Elena, quienes fueron allanados por fuerzas de orden el 7 de junio de ese año. Carabineros llegó a la población buscando a miembros del MIR que estaban implicados en el secuestro de un periodista de derecha en Concepción. Víctor Toro escribió en la revista Punto Final:

"queremos llamar a los pobladores a defender su dignidad, sus hogares, por todos los medios a nuestro alcance: la lucha permanente contra este gobierno y los que vengan (y representen a este sistema), hasta que llegue el día en que campesinos, obreros y estudiantes, lleguen al poder como ya se logró en Cuba... iPatria o muerte: venceremos!" (Punto Final, 29-VII-1969).

Durante 1970 se concretó la alianza entre pobladores y el MIR con la emblemática toma de sitio del campamento "26 de enero", en la que participó activamente Víctor Toro, consolidándose como dirigente poblacional en la época. Toro militó en el MIR desde sus primeros años de creación y fue miembro del Comité Central, fue obrero minero, textil y metalúrgico, también se desempeñó como activista sindical durante los años sesenta.

Esta toma de terreno se realizó durante varios días que, entre desalojos e ir y venir de familias al lugar, finalmente, se estableció en la madrugada del 26 de enero de 1970, representando una acción directa promovida por el MIR, bajo su estrategia de movimiento de masas en alianza con los pobladores. Sobre la ocupación, Punto Final, una revista que cubrió las manifestaciones de las izquierdas revolucionarias y se mantuvo más bien crítica de las institucio- 
nales, publicó al respecto: "El jueves 22 de enero pasado quinientas familias sin casa procedieron a ocupar 'ilegalmente' los terrenos que están junto a la población 'La Bandera', a la altura del paradero 28 de Gran Avenida" (Punto Final, 17-II-1970). Sobre esta materia, Víctor Toro dijo al mismo medio:

"Los pobladores han recorrido todas las oficinas de CORVI y CORHABIT, en busca de solución, pero sin resultado alguno... como de costumbre. Frente a toda tramitación burocrática y que sólo conduce a no solucionar nada, los pobladores han acordado llamar a todos los Campamentos de sin casa que hay en Santiago a lanzarse en una campaña de movilización permanente para lograr la solución de nuestros problemas... Hasta este momento la única organización política que ha colaborado directamente con los pobladores del campamento '26 de enero' ha sido el MIR" (Punto Final, 17-II-1970).

Los pobladores entrevistados manifestaron: "Estamos muy agradecidos a estos compañeros revolucionarios, quienes han planteado públicamente que estarán junto a nuestras luchas hasta las últimas consecuencias" (Punto Final, 17-II-1970). Detrás de esta afirmación existía la emergencia de un discurso más radicalizado que profundizaba y publicitaba la movilización de pobladores en el escenario nacional, demostrando un interés mayor por parte de estos actores; la activación de acciones que potenciaban la resolución del problema habitacional (Garcés, 2014: 411). En este contexto y según anunció el diario Clarín, los pobladores de '26 de enero', acompañados por Víctor Toro, marcharon hacia la CORVI, llamando a la adherencia a los demás campamentos instalados en el recorrido que emprendieron; "de una callampa a otra fueron los sin casa de la toma 26 de enero" (Clarín, 11-II-1970).

Con esta primera muestra de influencia política del MIR en el campamento '26 de enero' se manifestó una visibilización importante respecto al problema de la vivienda, al menos en Santiago. La acción del MIR en conjunto a los pobladores, alcanzó rápidamente niveles de alta publicidad, por sus formas de negociación con las masas y autoridades del gobierno. Dentro de estas acciones destacaron las "milicias populares", que posteriormente articularon los "tribunales populares", generando debates a nivel nacional. También sobresalió la organización del "Congreso Provincial de Pobladores" en marzo de 1970, tras el que se manifestó públicamente la alianza entre pobladores y el MIR, bajo un discurso revolucionario (Garcés, 2014: 410).

Aquellos mecanismos de defensa que organizaron los pobladores y el MIR, se articularon en un sistema de vigilancia permanente en los alrededores del campamento, como en su interior. El propósito consistió en mantener el orden entre los pobladores y protegerse ante la posible represión de la policía. Las acciones que realizaban los milicianos al interior, se relacionaron con la mantención de la disciplina entre los pobladores; por ejemplo, controlar el ingreso 
o estancia de pobladores alcohólicos, sancionar la violencia intrafamiliar que esto podría acarrear y evitar robos o hurtos a las casas de los pobladores.

Según Punto Final, los pobladores del campamento '26 de enero' "se han dado una organización que quizás haga escuela en el futuro. La base de esa organización son las milicias populares" (Punto Final, 31-III-1970). De manera similar lo propone Boris Cofré, respecto al posterior campamento Nueva La Habana en La Florida, afirmando: "el campamento '26 de enero' es un antecedente fundamental de la experiencia del Nueva La Habana" (2007: 50). Este sistema de vigilancia y protección habría adquirido una orientación diferente a la que tuvieron las guardias que hasta entonces habían practicado los pobladores, pues con la influencia política del MIR desde 1970, la formación de milicianos ahora tendría un enfoque revolucionario, con alto nivel de militarización, por ende, con tácticas de autodefensa y uso de armas especializado.

La experiencia de organización del campamento '26 de enero', estimuló -aún más- las tomas de sitios en todo el país ${ }^{9}$, y generó instancias de reunión entre pobladores de distintas zonas, una de ellas fue el Congreso Provincial que organizó el campamento '26 de enero' entre los días 27 y 29 de marzo. Una nueva forma de organización poblacional, articulada por las "milicias populares" que promovió el MIR, demostraba que la lucha por la vivienda iba adquiriendo espacio en el panorama nacional, además de una importante atención de los medios de comunicación. Era necesario promover aquella forma de organización entre los pobladores del país, para lo que se llamó a un congreso al que llegaron dirigentes de variadas regiones.

"asistieron representantes de otros siete campamentos de Santiago, de 32 Comités de Sin Casa de Santiago, Puerto Montt, Talcahuano y Concepción, así como estudiantes universitarios y dirigentes sociales y políticos, entre los que destacó la presencia de Clotario Blest, ex presidente de la CUT y de Sergio Ruz, miembro del Comité Central de la Juventud Socialista" (Garcés, 2014: 412-413).

Uno de los pocos medios que difundió las discusiones del encuentro, fue el diario Las Noticias de la Última Hora, el que anunció "Los sin casa de Santiago hacen oír su protesta". Según este medio, los pobladores del campamento ' 26 de enero' manifestaron:

9 Las tomas de sitios eran procesos con una larga trayectoria, prácticamente, surgían al mismo tiempo que se fundaban las ciudades. Eso sí, desde mediados del siglo XX se intensificaron, teniendo un eje central importante en la toma de "La Victoria" en 1957. Durante el año 1970, la prensa informó sobre variadas tomas de terrenos, la mayoría de ellas en Santiago. Si bien el campamento '26 de enero' marcó un punto de inflexión durante el año, las ocupaciones espontáneas venían sucediéndose con fuerza previamente. Ver "Chillán: Violencia policial contra pobladores", Punto Final, 6-I-1970: 28. "Se tomaron terreno", Clarín, 1-II-1970: 8. 
"Hemos adquirido una experiencia en lucha. Sabemos que en otros sectores también ello ha sucedido. Creemos que la discusión honesta de distintos puntos de vista, de distintas experiencias en formas de organización, de distintas concepciones generales, hará surgir una rica síntesis, que será la base estratégica y la fundación clásica de un combativo frente de clase" (Las Noticias de la Última Hora, 28-III-1970).

El Congreso fue convocado por un órgano específico del MIR, que se creó especialmente para movilizar a los pobladores; el Movimiento de Pobladores Revolucionario (MPR), éste se subordinó a la Jefatura Provincial Revolucionaria (JPR), una dirección creada durante el Congreso. Víctor Toro, dirigente del MPR, dio un discurso en la inauguración del Congreso, expresando:

"Estamos luchando por formar una sociedad socialista, para hombres también socialistas, es decir, para hombres nuevos en el sentido total de la palabra. Esta labor ya ha comenzado, y con ella debemos prestar suma atención a la rectificación de todos los errores. Dentro de los campamentos y poblaciones, las asambleas generales de pobladores deberán aprobar códigos de justicia, fijando normas con sus correspondientes sanciones, que las milicias populares se encargarán de hacer cumplir fielmente" (Las Noticias de la Última Hora, 28-III-1970).

La realización de esta reunión no estuvo exenta de polémicas, sobre todo, entre las izquierdas, pues el diario El Siglo, de propiedad intelectual del PC -partido que presentó constantes tensiones políticas con el MIR-, publicó una noticia en la que acusó al Congreso Provincial de Pobladores de "divisionista", y de haber pasado por sobre el Comité Provincial de Sin Casa. (E/ Siglo, 29-III-1970).

Con esta reunión, que agrupó a los pobladores y dirigentes del MPR, quedó establecida una concepción respecto al problema habitacional, pero más que definir una posición por la lucha de la vivienda, se trazaron las líneas que guiarían la construcción de un sujeto nuevo, organizado y disciplinado, que debía expandir su movimiento, y que era -por sobre todo- revolucionario y defendía la vía armada. En este sentido, y como propone Vicente Espinoza, "En términos de contenidos, el aspecto más relevante de este congreso fue la afirmación de la lucha armada como única alternativa para Chile. La lucha de los sin casa quedaba integrada y hasta subordinada a ese objetivo" (1988: 304). Comenzaba a concretarse una lucha que no se enfocaba de lleno en resolver el problema de la vivienda, sino más bien en un movimiento amplio y generalizado, que buscó terminar con la desigualdad social y los problemas que afectaban a una diversidad de actores que poco se relacionaban con el problema habitacional, como el caso de trabajadores y estudiantes. Sin embargo, a través de la afirmación de Víctor Toro, se puede apreciar desde ya la difusión de esta consigna generalizada: "Este frente de clase deberá 
asumir clara y responsablemente su papel histórico, consciente siempre de la incapacidad absoluta del actual sistema de injustas diferencias sociales, para solucionar integralmente sus problemas" (Las Noticias de la Última Hora, 28-III-1970).

A medida que pasaban los meses, las tomas de sitios aumentaban y con ellas las alianzas entre pobladores y organismos políticos. La prensa informaba frecuentemente sobre ocupaciones de terrenos eriazos de diversa propiedad, dentro de ellas interesan las tomas de "Ranquil", "Elmo Catalán" y "Magaly Honorato", pues en éstas participó el MIR y, fueron las que en noviembre de 1970 conformaron el campamento Nueva La Habana, en la actual comuna de La Florida. En regiones también hubo tomas de sitios, como la toma del campamento "Lenin" en Talcahuano, en la que también participó el MIR (Punto Final, 26-V-1970).

El 7 de julio nacieron los campamentos "Ranquil" y "La Unión", el primero surgió a partir de la toma de un terreno de la Iglesia Católica, en el Convento la Inmaculada Concepción en La Granja, y el segundo en un sector cercano, ambos en la avenida Santa Rosa (Las Noticias de La Última Hora, 19-VII-1970). El campamento "Ranquil" 10 -que se conformó de unas mil doscientas familias que posteriormente construyeron el campamento Nueva La Habana- tuvo una influencia organizativa del MIR, bajo una estructura similar a la del campamento ' 26 de enero', es decir, principalmente, a base de las "milicias populares", principal elemento mirista que integraron los pobladores, puesto que venían hace, prácticamente, veinte años ejecutando formas propias de organización poblacional, que incluían policlínicos, escuelas, jardines, centros deportivos y centros culturales. En un principio, en "Ranquil", las familias recibieron ayuda externa de diversos actores, además de los dirigentes del MIR, de sacerdotes católicos, el sindicato de trabajadores del diario Clarín, el Centro de Estudiantes de Ingeniería de la $U$. de Chile y algunas radios. Una vez establecido el campamento "Ranquil", la JPR anunció, según Punto Final: "las tomas de terreno son hechos ilegales, organizados por el pueblo que es impulsado por sus necesidades más vitales. Esto nos hace ver que las tomas de terreno seguirán. Mientras existan chilenos sin techo, habrá tomas de terreno" (Punto Final, 21-VII-1970).

Además, en este anuncio inauguraron la consigna "Casa o muerte, venceremos", la que posteriormente impulsó la creación de nuevas consignas entre los pobladores de Nueva La Habana, como "Mierda o muerte", em-

10 El nombre del campamento conmemoró el enfrentamiento entre campesinos y fuerzas de orden en el fundo "Ranquil", en la provincia de Malleco, ocurrido en 1934. En aquel acontecimiento, los campesinos se sublevaron contra los patrones y provocaron un levantamiento que terminó en un enfrentamiento armado. 
pleada cuando protestaron contra el alcalde de La Florida por la suspensión municipal del retiro de basuras en el campamento. ${ }^{11}$ Con el empleo de estas consignas, se manifestaba una influencia política del MIR evidente entre los pobladores, pero es preciso señalar que, para este caso, sólo se trataba de consignas, por tanto, no es propicio sugerir un nivel de politización profundo.

De manera similar se organizaron los pobladores del campamento Elmo Catalán; era un grupo de familias más pequeño, según informó el Clarín, alrededor de 362 familias sin casa, que ocuparon un terreno de la Universidad Católica en Quilín, comuna de Peñalolén (Clarín, 27-VII-1970). La toma se llevó a cabo el día 26 de julio, en conmemoración del frustrado asalto al Cuartel Moncada en Santiago de Cuba, acontecimiento que suele ser considerado el inicio de la Revolución Cubana, el 26 de julio de 1953. ${ }^{12}$ El nombre del campamento se asignó en conmemoración al periodista chileno e integrante del ELN boliviano (Ejército de Liberación Nacional), Elmo Catalán, asesinado por la CIA en Bolivia, durante junio de 1970. Los pobladores anunciaron que su acción era "una forma de presionar ante las autoridades para que se ocupen de una vez por todas del problema que los afecta" (Clarín, 27-II-1970). De esta manera y, como lo habían manifestado en variadas ocasiones, los pobladores sostenían que las tomas de sitios no siempre eran mecanismos de ocupación definitiva, sino también una acción de presión y, por tanto, de negociación y alianzas con una diversidad de actores, como miembros de la Iglesia Católica, políticos y autoridades estatales.

El campamento "Magaly Honorato" surgió de una toma de parcelaciones privadas entre los paraderos 12 y 14 de Gran Avenida, en la comuna de San Miguel. Con fecha 23 de agosto de 1970, según anunció el Clarín, al campamento se fueron sumando familias desde la madrugada, que resultaron ser alrededor de 325 (Clarín, 23-VIII-1970). El nombre de éste fue asignado en memoria de la fallecida profesora mirista Magaly Honorato, quien se suicidó tras un interrogatorio que le hizo la policía política.

Además, durante el mes de agosto, los pobladores integrados en el MPR, apoyados por estudiantes adherentes al MIR de la U. de Chile y U. Católica, se tomaron una torre en construcción de la "Remodelación San

11 Este acontecimiento fue relatado por Uberlinda Torres, una ex pobladora del campamento Nueva La Habana, quien contó que frente a la suspensión municipal del retiro de basuras en el campamento, los pobladores recogieron sus desechos y fueron a dejarlos a la casa del ex alcalde, mientras protestaban: ¡Mierda o muerte!”. Este suceso también fue constatado por El Rebelde, 5-X-1971: 3.

12 El acontecimiento del 26 de julio de 1953 fue un profundo fracaso, puesto que los revolucionarios tuvieron que detener el asalto ante el atrincheramiento de los oponentes, que se encontraban al interior del recinto con una evidente superioridad armamentística. Aun así, este evento denominó al movimiento revolucionario cubano, conocido después como el M26. 
Borja", para adquirir mayor visibilidad y ser atendidos por las autoridades. (Clarín, 18-VIII-1970). En paralelo, un grupo de pobladoras se instaló en las afueras del Congreso Nacional y comenzó una huelga de hambre, con el fin de increpar a los parlamentarios por promesas habitacionales incumplidas: "Estamos luchando y vamos a seguir en la pelea aunque nos muramos, porque nuestro grito de guerra lo trajimos para acá: Casa o Muerte" (Punto Final, 1-IX-1970). En esta protesta participaron algunas pobladoras que posteriormente llegarían al campamento Nueva La Habana, entre ellas, "38 mujeres de los campamentos Ranquil, 26 de julio, La Unión, Elmo Catalán y Rigoberto Zamora" (Las Noticias de la Última Hora, 18-VIII-1970).

Tras ambos incidentes que lograron captar la atención de las autoridades estatales, se iniciaría un proceso de negociaciones entre estos últimos, los pobladores y la ayuda técnica de los académicos y estudiantes de la Universidad de Chile. Dentro de estos acuerdos se insertó la negociación que dio origen al campamento Nueva La Habana en noviembre de 1970. Es importante señalar que, en este contexto de negociaciones y la posterior elección de Salvador Allende como presidente, el MIR llamó a un nuevo Congreso de pobladores los primeros días de octubre del mismo año. La reunión se inauguró como el Primer Congreso Nacional de Pobladores y se realizó durante los días 10, 11 y 12 de octubre. El carácter central de la reunión fue la aprobación del gobierno de la Unidad Popular y el reconocimiento de Salvador Allende como presidente. De acuerdo a esto, se acordó aprobar

"un plan de trabajo para ser aplicado a partir de este momento. El primer punto es la discusión y elaboración de plataformas reivindicativas en cada frente, junto con el estudio del programa de la Unidad Popular y la organización de comités de defensa del triunfo. Se estima que este será el principal papel a cumplir por las milicias" (Punto Final, 27-X-1970).

\section{Fundación del campamento Nueva La Habana}

Como se mencionó anteriormente, el surgimiento del campamento Nueva La Habana fue posible a partir de la negociación tripartita encabezada por el Ministerio de Vivienda y Urbanismo, personal técnico de la Universidad de Chile y la JPR, integrada por el MIR y pobladores adherentes. Según la investigación de Boris Cofré y la información recogida de la documentación del Instituto de Vivienda, Urbanismo y Planeación (IVUPLAN, Facultad de Arquitectura $U$. de Chile), de las negociaciones mencionadas entre este organismo, la JPR y las autoridades estatales, "surgió una solución al problema habitacional de los sin casa agrupados en la JPR, así los dirigentes del MIR reafirmaron su legitimidad y los pobladores confirmaron sus nuevas formas de enfrentar sus antiguos problemas" (Cofré, 2007: 87-88). 
Así, entre organismos institucionales como la CORVI y la CORMU, organismos revolucionarios como la JPR y el MIR, y los pobladores adherentes, se pactó un acuerdo con fecha 28 de agosto de 1970 que manifestó:

"a) Las respectivas universidades afectadas se encargarán de dar ayuda técnica al problema, b) El Ministerio materializaría las proposiciones técnicas que reciban de las universidades, c) Los pobladores aceptarían ser encuestados por las universidades y se abstendrán de acciones violentas mientras comprobaran que el problema avanzara hacia una solución concreta. Al mismo tiempo, cooperarían en todo lo posible y necesario a la materialización de los proyectos aprobados" (Cofré, 2007: 88).

Aquella negociación la llevaron a cabo Ángel Hernández, vicepresidente de la CORVI, Eduardo San Martín, vicepresidente ejecutivo de la Corporación de Servicios Habitacionales, Jaime Silva, vicepresidente de la CORMU, Antonio Labadía, director general de Planificación y Presupuestos, César Díaz, subsecretario de Vivienda y Urbanismo, Fernando Kusnetzoff, decano de la Facultad de Arquitectura y Urbanismo de la U. de Chile, representantes de la U. Católica ${ }^{13}$ y los dirigentes de la JPR (Cofré, 2007: 89). La variedad de actores participantes en este acuerdo, da cuenta de una alianza que pareciera tener como objetivo una asesoría técnica a favor de la planificación habitacional en Nueva La Habana. Sin embargo, también demuestra un acuerdo político, en el que es interesante la participación de la U. de Chile, ya que a esta casa de estudios no le correspondería un rol político, sino más bien uno educativo, no obstante, durante el gobierno de la UP, se mantuvo influida por las ideas del socialismo.

Respecto a la discusión de la asignación del terreno para el campamento Nueva La Habana, se acordó que el "terreno ubicado al sur de Av. Departamental y al poniente de Av. Tobalaba (Fundo Los Castaños)" sería el elegido. "La superficie total del Fundo era de 86 hectáreas, de las cuales se ocuparían 56 hectáreas para la población Nueva La Habana" (Cofré, 2007: 90-91). De esta manera, la relocalización de los campamentos "Ranquil", "Elmo Catalán" y "Magaly Honorato", sería en el ex Fundo Los Castaños, en la actual comuna de La Florida.

"Por carta ingresada, al sub-departamento de terreno... de la CORVI, con fecha 2 de octubre de 1970, los propietarios del fundo Los Castaños ofrecieron estos terrenos a un precio de $\mathrm{E}^{\circ}$ (escudos) 7,50 el m2., pagaderos al contado, e hicieron presente además, que existían

13 Respecto a la participación de miembros de la U. Católica, es importante señalar que tras la Reforma Universitaria de 1967, esta casa de estudios impulsó un importante trabajo de integración social y compromiso con los problemas sociales, uno de ellos fue el problema habitacional, concebido como una de las manifestaciones de desigualdad social que existía en el país. 
casas patronales, de inquilinos y otras mejoras, cuyo valor debería agregarse al terreno" (Cofré, 2007: 92).

La compra realizada con fondos estatales, se transó en 3.906.550 escudos, "por carta de fecha 29 de octubre de 1970, los representantes de la comunidad Domínguez y otros, dueños del fundo Los Castaños, aceptaron este valor y vendieron al Estado dicha propiedad" (Cofré, 2007: 92). Tres días después, los pobladores de los tres campamentos mencionados, llegaron al terreno, la mayoría de ellos trasladados con ayuda de IVUPLAN, otros se trasladaron con sus propios medios.

Si bien el acuerdo que se pactó entre la institucionalidad y la Jefatura Provincial Revolucionaria logró asignar terrenos para varias familias sin casa ${ }^{14}$, no remedió del todo el problema habitacional. Durante el mes de noviembre resulta fácil encontrar noticias en la prensa que anunciaban nuevas tomas de sitios y protestas por parte de los pobladores hacia las autoridades, como de discusiones parlamentarias en torno a los planes habitacionales, con especial participación de la Democracia Cristiana. ${ }^{15}$ Así, se evidenciaba que el problema habitacional persistía, aun cuando otros medios, como Punto Final, no prestaban mayor atención a esta continuidad, sobre todo si se trataba de deslegitimar la gestión de la UP en materia de vivienda o mostrar la participación de otros organismos políticos junto a los pobladores.

De esta cobertura mediática, es importante señalar que la activa y creciente participación de la DC en defensa de los pobladores no fue casual, pues podría concebirse como una forma de enfrentamiento con las izquierdas en el terreno poblacional, bajo el anticomunismo que los democratacristianos difundieron en el período. En este sentido, las tomas de sitios comenzaban a combinarse con intereses propios de la DC, conformando formas de protesta y cuestionamientos a la gestión habitacional de la UP.

El ex fundo Los Castaños se entregó a los pobladores con luz eléctrica, nivelación de suelo y desvío de canales, es decir, un terreno habilitado para

14 Las instituciones y autoridades mencionadas en el contexto de acuerdo, también discutieron y asignaron terrenos para otras familias que no eran de los campamentos "Ranquil", "Elmo Catalán" y "Magaly Honorato". Se firmó también un acuerdo para asignar un terreno en la comuna de La Cisterna, al sur de la población José María Caro, para los pobladores del campamento "26 de julio".

15 Revisar "Moción parlamentaria. Buscan solución al problema de las ocupaciones ilegales", La Tercera, 12-XI-1970: 5. "Jefes de gobierno dieron vuelta por poblaciones", La Tercera, 16-XI-1970: 7. "Que no se toque un pelo a pobladores irregulares", La Tercera, 18-XI-1970: 10. "A puñetes corretean a invasores de población", La Tercera, 19-XI-1970: 2. "Tomas de viviendas son una acción concertada", La Tercera, 19-XI-1970: 8. "Les ocuparon terrenos a modestos productores", La Tercera, 22-XI-1970: 2; "Nueva legislación sobre ocupaciones ilegales", La Tercera, 29-XI-1970: 3. 
levantar construcciones sencillas, pues para construcciones sólidas hacía falta una red de alcantarillado.

El traslado hacia el sitio se realizó con camiones, algunos fueron prestados por IVUPLAN, municipalidades o se conseguían por medios propios. Miguel Arriagada, poblador proveniente de la toma de "Ranquil", relató al respecto:

"Nos vinimos en camión, en vehículo así...cada uno como podía, no era tanto lo que teníamos allá; una carpa, una cama, nada más... Era re poco lo que había que echar, la carpa y algunas cositas no más. Los mismos que estaban ahí peleando por una casa (los pobladores de Ranquil), muchos trabajaban en feria y tenían sus camioncitos, otros camioneta, una onda así... y la municipalidad (de La Granja) también nos facilitó unos camiones para que nosotros nos cambiáramos, porque a ellos les urgía que el terreno se desocupara" (Entrevista personal, Miguel Arriagada, XII-2015).

Si bien la instalación del campamento Nueva La Habana pareció bien organizado, con gran adherencia de pobladores y un nivel alto de simpatía con el MIR, hubo situaciones entre los pobladores que reflejaban falta de convencimiento en la adherencia política, que además, se entremezclaba con asuntos personales. Algunos testimonios representan esta conducta, por ejemplo el de Cristina Garrido:

"Yo me vine para acá, pero no le había dicho a mi marido que el campamento era del MIR. Ahí mismo me dijo que él no se vendría a vivir acá. Porque en ese tiempo igual había temor hacia eso de la cosa revolucionaria y mi marido no estaba muy de acuerdo con eso. Pero a mí no me importaba, lo que yo quería era mi casa, así que me quedé no más con mis hijos y mi mamá" (Fuentes, 2007: 46-47).

Otro caso fue el de Dina del Carmen, para quien el aspecto personal era el único presente, más allá de cualquier consideración política:

"Llegué aquí con mi marido, pero a él no le gustó mucho vivir aquí y se fue, alcanzó a durar dos semanas no más. Y ahí yo me quedé sola con mis tres hijas... Me tuve que quedar sola con mis hijas. Pero eso no me importó porque de alguna manera me las arreglaría y si me quedaba les podría dar una casa a ellas" (Fuentes, 2007: 46).

Las mil setecientas familias ${ }^{16}$ recién instaladas en el ex fundo Los Castaños, se organizaron en "24 manzanas y cada manzana contaba con 64 sitios en

16 Según Sebastián Leiva eran 1.536 familias, revisar en "De la toma de terrenos a la toma del poder: el campamento 'Nueva La Habana' y una nueva óptica para la movilización 
que vivían 63 familias y un sitio era destinado a sede social" (Garcés, 2003). Algunos pobladores recuerdan que habían 65 o 66 sitios de $3 \times 5$ mts., y la mayoría coinciden en que se trazaron 24 manzanas ordenadas con letras desde la "A" a la "H", y cada una tenía una directiva respectiva, compuesta de tres delegados. Según Uberlinda, el nombre que dieron al nuevo campamento se eligió, mediante

"elecciones democráticas, por asamblea general, donde se presentaron tres nombres y esos tres nombres fueron aprobados por la comunidad... el primer nombre era 'Fundo Los Castaños', otro nombre que no me acuerdo realmente, y el último era 'Nueva La Habana', tomábamos nuestras decisiones en asamblea democráticamente y tratábamos de ser solidarios, compartir... es debido a eso que dijimos 'es bonito el nombre Nueva La Habana' y se fue en votación y ganó la mayoría" (Entrevista personal, Uberlinda Torres, IX-2016).

Cuando se repartieron los sitios a cada familia, Irma recordó que:

"Nos entregaron un pedazo de tierra que nos dábamos vuelta pa' allá y chocábamos con una muralla, nos dábamos vuelta pa' acá y chocábamos con otra... Pero al fin y al cabo fue la gran solución que nos dio el MIR... fuimos harto molestosos eso sí, nosotros salíamos a protestar todos los días casi" (Entrevista personal, Irma Mella, III-2016).

Según afirma Boris Cofré, "posterior a este proceso fundacional otros pobladores organizados e individuales se incorporaron al campamento, previo acuerdo con los dirigentes, entre otras razones, porque existía aún espacio en los terrenos para recibir a más pobladores" (Cofré, 2007: 110-111). De esta manera, la instalación de las familias agrupadas en la JPR que llegaron al ex fundo Los Castaños, se realizó de forma más o menos organizada, como solían ser, históricamente, la mayoría de las ocupaciones de sitios, ya sean de carácter ilegal, o por acuerdos de las dirigencias e instituciones estatales.

\section{Organizaciones y frentes en el campamento Nueva La Habana}

La organización general de Nueva La Habana fue similar a las formas que adoptaron los pobladores en sus tomas de origen, con una influencia política del MIR articulada en frentes de acción, entre ellos, las milicias populares, que pertenecían al frente de vigilancia. Sin embargo, estas milicias habrían

poblacional", Revista de Historia Social y de las Mentalidades, №6, primavera, 2002, pp. 109-123. 
desaparecido en enero de 1971, dado su "descrédito" desde octubre de 1970. Irma y José relataron: "lo que sí, todo estaba organizado por el MIR", "se organizó (el campamento) en base a las ideas del MIR, se elegía un presidente por cada manzana, se elegía una directiva y nos reuníamos una vez por semana en la jefatura para ir organizando trabajos..." (Entrevista personal, José Gutiérrez, XII-2015).

Otros frentes de acción fueron los de salud, áreas verdes, madres, bomberos, construcción, cultural y comercio. Sin embargo, aquella estructura organizativa no se articuló desde un principio, pues los dos a tres primeros meses, los pobladores se ocuparon de construir sus mediaguas, emparejar terreno, conectarse a la luz de la calle central, en definitiva, instalarse adecuadamente y provistos de los servicios básicos a los que podían acceder. Por tanto, en este período de instalación fue más urgente construir que organizar, "lo que debilitó la participación de éstos (los pobladores) en las organizaciones comunitarias" (Cofré, 2007: 113). De esta manera, los primeros meses del año 1971 se inició aquella forma de organización poblacional, que además se caracterizó por ser sectorial y funcional, comprendiendo a los frentes mencionados, y por otra parte, se compuso de una instancia territorial, que se encargó de organizar a las agrupaciones de la manzana, la asamblea general, el directorio y la jefatura.

De la organización de los frentes, el que más recuerdan los pobladores es el de "vigilancia", pues afirman que "se hacían guardias todos los días" y que

"cuando los buscaban (a ladrones), llegaban a buscarlos aquí carabineros o detectives, no entraban ellos a hacer el arresto, se tenían que dirigir a la guardia (Frente de Vigilancia), dar a conocer el problema y nosotros internamente los buscábamos, los hacíamos confesar y los entregábamos a los detectives con confesión y todo, y dónde tenían todos los robos y quiénes eran los demás. Entonces, la familia de esos muchachos u hombres que robaban, quedaba en observación; si ellos admitían de nuevo al ladrón en la casa, se iban todos pa' afuera, si delinquía otro, se iban todos igual, y si no querían irse los sacábamos en la noche, en andas y los dejábamos al otro lado de la calle, en el 'patio Siberia', donde se tiraba a todos los malos vividores, fuera del campamento" (Entrevista personal, Tomás Ireland, IX-2016).

Aquel procedimiento se conoció como "Tribunales Populares", que había creado el MIR en los campamentos donde ejercía influencia política. Aunque las formas extra-estatales habían sido habituales en la organización autónoma de los pobladores a lo largo del siglo XX, el MIR introdujo una administración de la justicia que no se había practicado antes en el mundo poblacional. Aquellos tribunales mantenían un sistema de legislación local extrajudicial, que hacia 1972 causó gran polémica en el panorama nacio- 
nal, motivando al diario El Mercurio a publicar un reportaje acerca de esta forma de justicia local, precisamente, en el campamento Nueva Habana. La sección se tituló "Campamento tiene policía propia. 'Tribunales populares', MIR impide entrada de carabineros" (E/ Mercurio, 3-V-1972). En otra edición del mismo medio, se publicó una entrevista realizada a Alejandro Villalobos, dirigente mirista del campamento Nueva La Habana, en la que éste sostuvo:

"Sucede que en reiteradas oportunidades hemos entregado delincuentes a Investigaciones y a los dos días los dejan en libertad. A nosotros la policía no nos da garantías, y de ahí que tengamos nuestros propios 'frentes de vigilancia'... No es que no se les deje ingresar (a Carabineros). Eso sí, ellos deben solicitar la autorización a las autoridades del campamento, y nosotros somos los encargados de llevar a los policías hasta el poblador que ellos buscan. Lo que no aceptamos es que ingresen con el objeto de perseguir a la gente" (EI Mercurio, 4-V-1972).

En una entrevista realizada por Sebastián Leiva, quien ha estudiado la historia del campamento Nueva Habana, se relata un ejemplo cotidiano en el que intervino el Frente de Vigilancia con el procedimiento que, más o menos, señaló Tomás en su testimonio. Manuel Paiva contó en su versión:

"si se robaban un par de pantalones cuando estaban por ahí colgados en el patio, entonces, se buscaba dentro del empadronamiento cuáles eran los sospechosos y se encontraban ahí y se traía al tipo, se le tenía una noche detenido y se le entregaban algunas tareas, o sea, buscando la reeducación del individuo. Se le daban tareas como leer el «Manifiesto Comunista», el "Qué hacer», textos de ese tipo, y se le daban por ejemplo unos quince días para leerlos y diariamente tenía que ir a dar exámenes sobre la lectura. En algunos casos tenía que hacer trabajos también para la comunidad... y le daban como el trabajo más pesado que hacían ahí... O cuando ya se empezó a construir la población tenían que trabajar ahí construyendo casas, una semana ahí, sin derecho a sueldo, sólo con la alimentación" (Leiva, 2002: 115).

De esta manera, se buscaba "reeducar" a los pobladores que se encontraban en una situación carente. Las tareas de leer el "Manifiesto comunista" o el "Qué hacer", como mencionó Manuel Paiva, dan cuenta de otro elemento fundamental en el proceso de influencia política del MIR en Nueva Habana, y eran oficios indicados para otros casos de sanción, por ejemplo para alcohólicos que golpeaban a sus esposas e hijos.

Otro de los frentes fue el de salud, que contempló diversas acciones, en ellos trabajaban mayoritariamente mujeres, las "milicianas de salud", que se capacitaban respecto a hábitos de higiene, nutrición de los niños y otras 
áreas. Uberlinda e Irma recordaron que al campamento Nueva La Habana llegaban médicos directamente del hospital Sótero del Río para atender a pobladores y para capacitar a las pobladoras que estaban a cargo del Frente de Salud. De igual manera, Boris Cofré plantea que este Frente se vinculó con el gobierno de Salvador Allende, a través de los funcionarios del hospital. Sin embargo, afirma que en el campamento existió una "experiencia de salud comunitaria", que privilegió mantenerse al margen de la institucionalidad respecto a la toma de decisiones dentro del Frente de Salud, y que esta actitud fue estimulada por el MIR (Cofré, 2007: 170).

En paralelo, los médicos y profesionales de la salud se mostraron, a veces, reticentes a capacitar a las pobladoras, puesto que ellas no alcanzaban a tener conocimientos ni práctica médica para poner inyecciones o curar heridas, lo cual se sumó como una tensión más en la organización del campamento. Sobre esta situación, que manifestó una relación moderada entre el MIR y la UP en la época, es necesario plantear que los pobladores entrevistados no hicieron menciones de alguna estimulación por parte del MIR para establecer distancias con el sistema de salud estatal. No obstante, recordaron mayoritariamente la importancia de la asistencia básica sanitaria que les ofreció el gobierno de Allende, dando énfasis a la satisfacción de una primera necesidad, como es la salud, y no a una tensión ideológica entre el MIR y la UP. Es importante agregar a este respecto que la simpatía de los pobladores con la figura de Salvador Allende, al menos, durante la campaña presidencial y sus dos primeros años de gobierno ${ }^{17}$, puso de manifiesto el pragmatismo de estos actores, puesto que al mismo tiempo simpatizaban con el MIR.

Otro frente fundamental dentro del campamento, fue el de Cultura, cuyo principal objetivo fue la educación de los niños a través del Parvulario, también integrado por pobladoras, estudiantes y profesionales voluntarios. Dentro de las actividades que se impartían, estaban los paseos pedagógicos dentro del mismo terreno del campamento; en estos recorridos se le enseñaba a los niños botánica, especialmente sobre el cultivo y cosecha del trigo, puesto que había una plantación de éste en el lugar, que además de aprovecharse como materia prima para hacer pan, fue empleada también como un recurso didáctico para la enseñanza (Cofré, 2007: 159). En la escuela, que en un principio se instaló en buses viejos, como "buses-escuela", se les enseñaba a los niños sobre la historia de los mineros, campesinos y pobladores en Chile, promoviendo una educación alternativa a la institucional, pues el enfoque pedagógico se constituía a base de las ideas de la "lucha de clases" y de la unidad de los sectores populares en la construcción de un "poder popular"

17 Ver Carta al director "Opinión de un campamento", en Punto Final, 10-XI-1970, sección "Correo". 
(Cofré, 2007: 160). También existió enseñanza para adultos, la que se impartía por las noches y se enfocaba especialmente en la alfabetización de varios pobladores del campamento: para esto se creó una Comisión de Alfabetización.

Posteriormente, el Frente de Cultura se reestructuró considerando la influencia de la contingencia nacional, la que obligó a la Jefatura del campamento a crear un Frente de Abastecimiento de alimentos, para solventar el desabastecimiento que provocaron algunos gremios, empresarios, colegios profesionales y la oposición a la UP, con el fin de desestabilizar la economía y, por ende, debilitar el gobierno de Salvador Allende. Esta acción que encabezaron variados grupos oponentes, tuvo su mayor acción en el paro de camioneros de octubre de 1972, acontecimiento en el que un gran número de transportistas se paralizaron, impidiendo la circulación de alimentos y productos a lo largo del país. Para enfrentar esta situación, el gobierno de Allende creó un sistema de abastecimiento de alimentos; las Juntas de Abastecimiento y Control de Precios (JAP), que funcionaron como unidades administrativas de racionamiento a nivel local, creando convenios con el comercio detallista, es decir, con los almacenes de barrio que abastecían los vecindarios. Pero los pobladores de Nueva Habana crearon un sistema paralelo, que funcionó a través del Frente de Abastecimiento y los proveedores industriales del área social, es decir, los pertenecientes al Estado.

Si bien en un principio, los pobladores de Nueva Habana se abastecieron a través de la administración de las JAP, lo hicieron por poco tiempo, puesto que surgieron problemas burocráticos que entorpecieron el funcionamiento y distribución de alimentos hacia todos los pobladores del campamento. Por estas razones crearon su propia organización, y con ella administraron más eficientemente el racionamiento.

En entrevista, María Farías, ex pobladora de Nueva Habana, explicó cómo funcionaba el Frente de Abastecimiento:

"formamos este Comando [Frente de Abastecimiento] que está compuesto por delegados de cada manzana; hay 23 manzanas muy bien organizadas. Este Comando trae la mercadería a un Almacén Popular que formamos. Cada delegado de manzana sabe cuántas familias tiene en su sector, y pide en este Almacén, las canastas que necesita, o las lleva en un carrito a su manzana y allí, en un local destinado a eso, las reparte a cada familia. Las canastas valen entre 300 y 350 escudos, depende de los productos que lleve... Ahorramos tiempo, es barato y nos evitamos estar haciendo colas todo el día" (Chile Hoy, I-1973).

De manera similar, José Gutiérrez, quien fue delegado de manzana, afirmó: "En esta población se formó la 'canasta popular' y nunca nos faltó nada, en ese momento teníamos lo que nunca pensamos tener, teníamos 
Nescafé, Cerelac..." (Entrevista personal, José Gutiérrez, XII-2015). Miguel Arriagada, que también fue delegado de manzana, recordó:

"Nosotros cada quince días íbamos a la Agencia Graham a buscar el alimento para las 48 personas de mi manzana. Y yo con el coordinador iba a buscar las canastas para todos y después organizábamos y repartíamos por ración, pero eso lo pagábamos, porque los pobladores nos daban la plata antes y con eso pagábamos allá..." (Entrevista personal, Miguel Arriagada, XII-2015).

Sin embargo, en torno a esta organización poblacional que pareció eficaz y de funcionamiento regular, Tomás Ireland, ex poblador de Nueva La Habana, explicó que surgieron problemas que enfrentaron a los pobladores, sobre todo por robos de alimentos por parte de algunos delegados de manzana; "Habían delegados que eran bien buenos para estirar las manos... Se hacían delegados para ver qué podían agarrar por ahí..." (Entrevista personal, Tomás Ireland, III-2016). Esta situación también la relató Irma Mella, afirmando: "Sí, sí habían delegados ladrones, no en la Jefatura, eran los de las manzanas" (Entrevista personal, Irma Mella, III-2016). Este inconveniente que recordaron Irma y Tomás, mientras los demás entrevistados lo negaron, pone de manifiesto indicios de irregularidades en el comportamiento de los delegados de manzana en torno al Frente de Abastecimiento, y es una probabilidad de fundamental consideración para comprender los encuentros y desencuentros entre los mismos pobladores y la influencia organizativa del MIR.

Frente a la amenaza que significó el paro de los transportistas en octubre, tanto para la UP como para las izquierdas revolucionarias, el MIR decidió priorizar el abastecimiento en el campamento, más que la aceleración de la construcción de viviendas en Nueva Habana, las que se habían comenzado a construir en 1971 por la CORVI. Sobre estas construcciones trabajaron varios pobladores del campamento, que se reunieron en el Frente de Trabajo, creado para remediar la cesantía y, también, para agilizar el avance, puesto que una participación interna prestó mayor vigilancia y control de la construcción. Además, según contaron los pobladores entrevistados, las familias debían abrir una libreta de la vivienda en la que iban depositando cuotas a plazo del valor total de la casa en construcción, para postular a la entrega, debían tener un mínimo de cuotas canceladas, registradas por la Jefatura del campamento. Así, el MIR estableció alianza con la CORVI para administrar las libretas de los pobladores de Nueva La Habana, dando cuenta, una vez más, de la relación tibia que mantuvo con el gobierno de la UP. Esta postergación de la vivienda causó desencuentros entre los pobladores y la dirigencia del MIR, puesto que el Movimiento no sólo privilegió la articulación del abastecimiento de alimentos en el campamento, sino que también resolvió profundizar la unidad de los sectores populares y vincular los Comandos Comunales con 
los Cordones Industriales, estos últimos creados para enfrentar la amenaza de la crisis de octubre y dirigidos por el Partido Socialista.

La UP decidió restar apoyo a las movilizaciones sociales para disminuir la radicalización política, que luego de la coyuntura de octubre de 1972 se presentaba más como un obstáculo que exacerbaba el conflicto político, que una salida a la crisis de legitimidad del gobierno. De esta manera, la Unidad Popular conformó un gabinete cívico-militar que restableció el orden institucional, ante un eventual quiebre, puesto que se acercaban las elecciones parlamentarias de marzo de 1973. En este escenario, el gobierno de Allende no apoyó los núcleos de organización obrera, campesina, ni poblacional, como los Cordones Industriales y los Comandos Comunales antes mencionados, lo que no significó que éstos dejasen de movilizarse; incluso, ante la acción desestabilizadora de la oposición, más se estimularon por grupos izquierdistas. Ante esta situación, las izquierdas que estaban dentro del gobierno de la UP, tuvieron divisiones respecto a las estrategias políticas que debían seguirse tras el paro de octubre y la amenaza de la oposición, como también las que debían determinarse para preparar las elecciones de marzo de 1973 (Punto Final, 27-II-1973).

Aquellos Comandos Comunales que estimuló el MIR estuvieron integrados, en parte, por pobladores, además de estudiantes, y fueron articulados para reunir a los sectores populares bajo un estado prerrevolucionario. Estos comandos se propusieron acelerar la materialización de la revolución socialista, puesto que el MIR evaluó que el gobierno de la UP no contribuía a estimular efectivamente el proceso revolucionario, y que estaba siendo amenazado por la oposición, que en junio de 1973 amenazó nuevamente al gobierno, con un fallido golpe de Estado encabezado por un grupo de las FF.AA (Cofré, 2007: 203-204). Sin embargo, la unidad y fortalecimiento de los Comandos no se logró, puesto que lograron reunir a pocos sectores populares y a grupos urbanos que eran menos numerosos, como estudiantes secundarios y pobladores, en contraste a los obreros, que se reunieron en los Cordones Industriales y sí lograron mayor cohesión.

Los pobladores del campamento Nueva Habana integraron los Comandos Comunales y participaron activamente cuando el objetivo se trataba de resolver problemas de abastecimiento y de organización general en torno a los problemas que los afectaban directamente. Durante el año 1973, continuó el desabastecimiento a nivel nacional, por lo que la prioridad se mantuvo sobre el funcionamiento del Frente de Abastecimiento del campamento, restando atención a los demás Frentes. A pesar de que en Nueva Habana se enfrentó con relativa eficiencia la falta de alimentos y productos básicos, a través de la organización comunitaria que se impulsó con el Frente y el Almacén Popular, en septiembre del mismo año la situación cambió drásticamente, y esa vez se trató de un quiebre definitivo del sistema organizativo al interior 
del campamento, desencadenado después del Golpe de Estado del 11 de septiembre de 1973.

Tras el bombardeo al Palacio de La Moneda, dirigido por las FF.AA., el derrocamiento del gobierno de la UP era evidente. En pleno bombardeo, y ante el ultimátum de renunciar al gobierno, Salvador Allende se suicidó. Con su muerte finalizó violentamente el proyecto socialista de la Unidad Popular en Chile. Los militares, dirigidos por Augusto Pinochet, atentaron no solo contra el Palacio de gobierno, sino también contra toda la institucionalidad republicana y democrática del país. La junta militar estableció una férrea dictadura, amparada en el terror de Estado, e inició una sistemática persecución política a las izquierdas, entre las que, ciertamente, destacaba el MIR.

Pocos días después del Golpe de Estado, las FF.AA. ingresaron violentamente al campamento Nueva La Habana, allanando las viviendas de los pobladores, deteniendo a varios hombres y atemorizando con disparos al aire. Alejandro Villalobos, el "Mickey", abandonó el campamento por su propia seguridad antes que llegaran a allanar el lugar los militares, entrando en la clandestinidad hasta 1975. Cuando estaba refugiado en Viña del Mar y, en una emboscada, agentes de la DINA lo asesinaron. Por su parte, los demás dirigentes que se quedaron en el campamento, fueron detenidos y trasladados a distintos centros de detención que ocuparon los militares, entre ellos el Regimiento de Puente Alto y el Estadio Nacional (Cofré, 2007: 226).

Según recuerdan los pobladores entrevistados, los militares los obligaron a cambiar el nombre del campamento, puesto que su denominación constituía un referente de la revolución socialista y las ideas marxistas, las que quisieron extirpar de la sociedad chilena tras su intervención. Irma Mella recordó este episodio:

"Cuando le cambiaron el nombre a esta población, los huevones (los militares) se subieron arriba de un estrado (y preguntaron): - '¿Cómo se llama esta población?', -'¡Nueva La Habana!', le dijimos nosotros, y el huevón (militar que dirigió el allanamiento) dijo: -'¡No! Hay que cambiarle el nombre'... No faltaron los huevones chupa medias (pobladores) (que dijeron) 'Nuevo Amanecer' (con voz burlesca)..." (Entrevista personal, Irma Mella, III-2016).

El cambio del nombre del campamento a "Población Nuevo Amanecer", se registró desde el día en que los militares llegaron a allanar y a detener a los militantes del MIR que se quedaron; también buscaron a Alejandro Villalobos en ese momento.

En octubre de 1973, la construcción de las casas dejó de dirigirse por la CORVI y pasó a manos de una constructora privada; "Cocivil Ltda.", la que coordinó la entrega de casas dos años después, en 1975, con el sistema de 
cuotas mínimas para postulación, dando cuenta de la privatización empresarial que inició el Régimen militar. En el proceso de entrega, no todas las familias de ex Nueva La Habana recibieron su casa, puesto que sólo algunos alcanzaron a depositar las cuotas requeridas por la constructora. Esta situación causó desencuentros entre los pobladores, incluso, hasta la actualidad; según los testimonios de Irma, Tomás, Uberlinda, José y Miguel, ellos no recibieron las casas edificadas. Los pobladores que recibieron sus casas, se trasladaron al sector más alto del campamento, donde se ubicó la edificación, por lo que hoy en día son llamados "los de arriba" ó "los de las casas de arriba", mientras los pobladores que no recibieron casas, se quedaron en la parte baja del campamento y hoy tienen sus casas por autoconstrucción. Aquella fórmula de privatización de la situación habitacional de Nueva La Habana, significó, en parte, la desmembración del campamento.

\section{Encuentros y desencuentros entre los pobladores de Nueva La Habana y el MIR}

Los problemas de convivencia que tuvieron los pobladores de Nueva Habana, se dieron, prácticamente, desde que llegaron al sitio concedido por el acuerdo entre el MIR y la UP, y continuaron hasta la desintegración del campamento en 1973, con situaciones como la mencionada anteriormente; las rivalidades entre los pobladores que obtuvieron sus casas entregadas por el Régimen Militar, y los que no. Detrás de la afirmación de Uberlinda, sobre la convivencia que tuvieron, hay elementos fundamentales para comprender situaciones de desencuentro en Nueva Habana, que claramente distan de visiones sesgadas e idealizadas respecto al estudio de la vida al interior del campamento. "Cuando hay una comunidad que está amontonada, siempre va a haber problemas, con el vecino, (o) que le pega el marido a la mujer..." (Entrevista personal, Uberlinda Torres, III-2016).

De manera similar, José Gutiérrez recordó que:

"el día viernes era el más complicado, cuando llegaba la gente de trabajar (hombres), llegaban peleando, pegándole a la señora, no traían plata, llegaban curados, se tomaban toda la plata... Algunos dirigentes se aprovecharon, porque veían a cabritas de 16 años y se metían con ellas, las dejaban embarazadas... De repente se agarraban del moño las viejas: '¡oye andai con mi marido!'. También veíamos peleas de matrimonios a fierrazos, esas cosas..." (Entrevista personal, José Gutiérrez, XII-2015).

Si bien ante estos problemas, la Jefatura, dirigida por el MIR, articuló el Frente de Vigilancia, fue difícil terminar con la violencia intrafamiliar, robos de ropa y alimentos, conflictos pasionales y todo problema que pudo surgir 
desde la cotidianidad en el hacinamiento y la precariedad en Nueva Habana. De esta manera, algunos pobladores se comportaron al margen del reglamento impulsado por el MIR para controlar el orden y convivencia al interior del campamento, desafiando elementos propios de la influencia política del Movimiento.

Pocos meses después de cumplir el primer aniversario, los pobladores de Nueva habana hicieron una autoevaluación a su organización poblacional, para la cual organizaron su Primer Congreso de Pobladores en febrero de 1972, durante tres días; 11, 12 y 13 de febrero. Esta instancia se presentó como un momento de autoevaluación respecto a la estructura organizativa que se había articulado en el campamento durante poco más de un año (El Rebelde, 1-II-1972). Según informó El Rebelde -diario oficial del MIR-, durante esta reunión fue que el Frente de Vigilancia planteó la formación de "Tribunales populares", lo que indica que durante el primer año del campamento aún no existía un sistema extrajudicial para enfrentar la delincuencia. Así, y como señaló Alejandro Villalobos, dirigente máximo del MIR en Nueva La Habana, dentro de los objetivos del Congreso estuvo el de impulsar "la conquista del poder local" que "mantenían las municipalidades", como también el tratamiento de la organización interna de Nueva Habana;

"Hay que crear los Consejos Comunales donde participen los pobladores y también los obreros, campesinos, estudiantes y soldados de cada sector. Que sean ellos los que decidan las políticas y no los alcaldes y autoridades que no nos representan... Además se han fijado nuevas metas. Aún falta solucionar el problema de la pavimentación, locomoción y una escuela adecuada. Las casas todavía no han sido entregadas" (El Rebelde, 15-II-1972).

Sin embargo, respecto a las alianzas entre pobladores, obreros, campesinos y estudiantes en torno a los Consejos Comunales, no hay mayor referencia en los testimonios de los entrevistados Probablemente, esto se debe a que esos núcleos apuntaban más a una unidad en favor de la revolución socialista, que a una lucha específica por la vivienda; principal propósito de los pobladores de Nueva La Habana.

Dos semanas después del Congreso, a fines de febrero, se realizaron elecciones para designar a una segunda Jefatura que lideró nuevamente Alejandro Villalobos, con 1.073 votos a favor. La lista del MIR, que integró, además, a otros pobladores, obtuvo un total de 4.522 votos, "colocando a la mayoría de sus candidatos en los puestos de la Jefatura. La lista de la UP obtuvo 2.983 votos y un representante a la Jefatura. Una tercera lista, de independientes, logró 882 votos, pero ningún cargo en la Jefatura" ( $E$ I Rebelde, 29-II-1972). De esta manera, se evidenció un amplio apoyo de los pobladores de Nueva Habana a la dirigencia del MIR, la cual se manifestó 
en poco más del $50 \%$ de los votos emitidos. La otra mitad se constituyó de las listas de la UP y los independientes, agrupando a un número importante de pobladores. Aunque las ideas izquierdistas, reunidas en las listas del MIR y la UP, alcanzaron cerca de un $85 \%$ de los votos en Nueva Habana, es necesario considerar que entre ambos organismos políticos no existió una unidad absoluta, sobre todo en términos de la práctica política de cada uno, la que estuvo claramente diferenciada entre una vía armada y otra pacífica para implantar el socialismo.

Por otra parte, el grupo independiente que se presentó con una lista a las elecciones, evidenció diferencias políticas dentro del campamento, generando situaciones de conflicto entre los propios pobladores, y manifestando que al interior de Nueva La Habana no existía una unidad política inquebrantable. Al respecto, en un testimonio rescatado por Boris Cofré, un poblador explicó:

"Aquí hay 4 o 5 personas que quieren formar una Junta de Vecinos, al margen de la organización del campamento. Nosotros (los dirigentes) no tenemos ni un inconveniente que la formen, siempre y cuando ellos tengan cosas más positivas que nosotros [los simpatizantes del MIR] para el bien del campamento" (Cofré, 2007: 186).

Uberlinda, ex pobladora de Nueva Habana, recordó las diferencias políticas internas, como también la indiferencia política de algunos pobladores;

"No había solamente gente del MIR, también hubo gente de la VOP, gente democratacristiana, gente del Partido Socialista, si aquí llegó de todo... No podemos decir que aquí llegaron sólo los miristas. Habían de diferentes posiciones, como gente que no tenía ni puta idea de política, ni de nada, solamente quería tener su casa, una casa digna..." (Entrevista personal, Uberlinda Torres, IX-2016).

Tras la reelección del MIR en la dirigencia de la Jefatura de Nueva Habana, en febrero de 1972, se plantearon ideas que complejizaron la organización interna en el campamento, como se mencionó anteriormente; la diversificación de Frentes de acción, la creación de "Tribunales Populares" y de "Comandos Comunales". Estas medidas, según Cofré, "profundizaron la experiencia de politización de los pobladores de Nueva Habana" (Cofré, 2007: 211-212). Sin embargo, muchos de los elementos que formaron parte de la influencia política del MIR, especialmente, la forma de organización poblacional, fueron percibidos por los pobladores como mecanismos que cooperaban en la agilización de la obtención de sus casas y en la seguridad de la vida cotidiana, más allá de una simpatía ideológica-política con las ideas del Movimiento Revolucionario. De acuerdo a este planteamiento, los pobladores entrevistados manifestaron que "(...) el Movimiento (MIR) organizó muy bien a la gente, muy bien, (fueron) compañeros que se la 
jugaron por los pobladores... Yo no milité, era simpatizante solamente, es que hay contradicciones con mi religión ahí po..." (Entrevista personal, Irma Mella, III-2016). "Eran buenas reglas las del MIR, no es que yo sea simpatizante, pero eran (las reglas) sin violencia. Nunca me inscribí en el MIR, yo participaba para organizar, nosotros estábamos juntos por querer tener una casa, una condición más holgada en la vida" (Entrevista personal, José Gutiérrez, XII-2015). "Yo no era del MIR yo era un poblador no más que organizaba las cuestiones de los demás pobladores..." (Entrevista personal, Miguel Arriagada, XII-2015).

"No éramos del MIR los pobladores, nosotros estábamos por una necesidad que era la vivienda, pero nos gustaba el régimen que tenía el MIR de organización... Yo nunca participé en el MIR, a lo mejor a mí me quedó mi proceso porque era muy lola... yo me eduqué aquí, me dieron la oportunidad de aprender, fui la partera y enfermera de mi sector" (Entrevista personal, Uberlinda Torres, IX-2016).

Uberlinda agregó que cuando iban a las marchas a protestar por la vivienda para agilizar la construcción de éstas, llevaban a los niños y ellos gritaban: "MIR, MIR, MIR!", pero que "los niños lo hacían y gritaban porque los papás lo hacían, repetían ellos, pero nunca se les enseñó... Ellos se sabían las consignas de memoria, unas cagaítas chicas gritando..." (Entrevista personal, Uberlinda Torres, IX-2016). Si bien, se puede proponer que la influencia política del MIR en el campamento Nueva La Habana alcanzó un nivel de penetración, es fundamental comprender cuáles fueron las razones que motivaron a los pobladores para adherir al Movimiento.

La alianza que formó el MIR con los pobladores desde 1969, cuando el Movimiento reestructuró sus bases e inició el movimiento de masas, se constituyó de varios elementos que estimularon el encuentro entre estos actores. Como se mencionó en la primera parte de este artículo, la acción movilizadora de masas que emprendió el MIR tuvo un propósito específico, que fue, primero, iniciar una agitación de los sectores populares como obreros, campesinos, estudiantes y pobladores, y, segundo, crear una cohesión ideológica-política entre estos grupos, ambos objetivos concebidos como estrategias que los condujeran más rápida y eficazmente a la revolución socialista en Chile.

Dada la activación del movimiento de masas, el MIR se posicionó como un organismo político que alcanzó una amplia visibilidad en el escenario nacional entre los años 1969 y 1973, puesto que este período sus dirigentes encabezaron numerosos asaltos a bancos, tomas de fábricas, expropiaciones en el campo y tomas de sitios urbanos. Este nivel de publicidad, que la prensa cubrió con frecuencia, se presentó como una situación conveniente para los pobladores, pues las demandas por la obtención de viviendas no 
habían sido acogidas eficazmente por el Estado, por tanto, la alianza con el MIR significaba una excelente oportunidad para visibilizar el problema habitacional que afectaba a los pobladores desde hacía 20 años. Como propone Palieraki, "difícilmente se puede afirmar que fuera una supuesta tendencia innata de las capas populares al socialismo y a la revolución armada lo que les condujo directamente al MIR" (Palieraki, 2014: 274).

Los pobladores estaban convencidos de que sus acciones debían causar un impacto público y mediático, para atraer la atención del Estado u otras instituciones y, así, formar alianzas con el fin de encontrar una salida al problema habitacional que los aquejaba; de esta convicción pueden entenderse las tomas de sitios, las protestas y, en general, toda acción callejera que encabezaron. De esta manera, el MIR se mostraba como un atractivo táctico para los pobladores, ya que les permitía estar presentes en el espacio público, beneficiándose de la notoriedad del Movimiento y de sus habilidades para salir del olvido (Palieraki, 2014: 278).

Los planteamientos de Palieraki son congruentes con las declaraciones de los pobladores entrevistados, puesto que ellos indicaron que su simpatía por el MIR se basó en una oportunidad para solucionar su problema habitacional, y no tanto por una coincidencia ideológica-política; por ende, ponen de manifiesto una conducta pragmática frente a la influencia política del MIR, que además, comenzó en otros campamentos fundados a partir de tomas de sitios, como el "26 de enero", "Magaly Honorato", "Elmo Catalán" y "Ranquil", para manifestarse con el mismo pragmatismo en el campamento Nueva Habana, levantado a partir del acuerdo entre el MIR, la UP y los pobladores. Aquella notoriedad de la alianza entre pobladores y el MIR, se habría manifestado inicialmente cuando anunciaron la convocatoria al Primer Congreso Provincial de Pobladores de agosto de 1970.

Con todo, la influencia política del MIR en el campamento Nueva La Habana, debe comprenderse en una lógica de encuentros y desencuentros con los pobladores, puesto que éstos sí simpatizaron con el Movimiento, sobre todo, cuando vieron que el MIR les mostraba algún signo de asistencia habitacional, pero al mismo tiempo, algunos pobladores desafiaban la estructura organizativa que dirigió el MIR, provocando desencuentros reflejados en conductas delictuales, violentas y alcohólicas. Además, a estos desacuerdos debe sumarse un número no menor de pobladores que no simpatizaba con el MIR, pero sí con otros partidos políticos, como también existieron pobladores que no mostraron interés por una simpatía política, solamente les interesaba adquirir una vivienda.

En términos generales, es necesario considerar que, como proponen Sebastián Leiva y Fahra Neghme, la presencia cuantitativa del MIR en las poblaciones durante el gobierno de la UP no fue elevada, puesto que de un total de ochenta y tres mil familias que vivían en campamentos, sólo seis mil de 
ellas lo hacían en campamentos dirigidos por el MIR, por tanto, se alcanzaba poco más de un siete por ciento de presencia en el mundo poblacional (Leiva y Neghme, 2000: 113). Según estos datos, se asumiría que todos los campamentos conformados por la participación del MIR, incluido Nueva La Habana, habrían presentado una simpatía absoluta, lo cual no fue así si se consideran los datos de las votaciones de la segunda Jefatura del campamento. En este sentido, es propicio reafirmar el planteamiento de Hugo Cancino: "El MIR ejerció niveles de influencia sobre segmentos políticamente radicalizados de un movimiento de pobladores que se encontraba organizativa y políticamente escindido en distintas organizaciones a nivel nacional" (Cancino, 1988: 347).

En estos términos, se puede proponer que no es apropiado idealizar sobre la influencia política del MIR en el mundo poblacional, acción que se dio con mayor fuerza durante el gobierno de la UP, en un contexto de permanentes tensiones entre las izquierdas chilenas, las que provocaron contradicciones en los pobladores, puesto que su nivel de pragmatismo frente a la simpatía con el MIR y con otros agentes -como Salvador Allende-, fue permanente durante el período, conducta que complejizó los niveles de adherencia, volviéndolos actores políticamente ambiguos. De acuerdo a esta realidad en Nueva La Habana, es fundamental señalar que aquellas tensiones y contradicciones socio-políticas también formaron parte de lo que sucedía en la sociedad del período. Así como los vínculos socio-políticos de las sociedades son complejos, también lo son en esferas sociales específicas, como el Nueva La Habana, dando cuenta de un clima general de contradicciones que envolvió aquella época, que además sumó esa idealización revolucionaria que distó de ser real.

El pragmatismo que demostraron los pobladores durante este contexto, debe concebirse en una perspectiva histórica, ya que esta conducta de los pobladores frente a los procesos de politización, presenta una continuidad que se posiciona en una lógica de anillos intermedios respecto del tiempo histórico lineal, permitiendo comprender este fenómeno político-social que han mostrado los pobladores en distintos períodos y contextos del siglo XX chileno.

\section{Referencias bibliográficas}

\section{Fuentes primarias}

a) Periódicos y revistas

Punto Final, Santiago, 1969-1973.

Clarín, Santiago, 1970.

El Siglo, Santiago, 1970. 
Las Noticias de Última Hora, Santiago, 1970.

El Rebelde, Santiago, 1971-1972

Chile Hoy, Santiago, 1973.

El Mercurio, Santiago, 1972.

\section{b) Entrevistas}

Poblador ex Campamento Nueva La Habana, Miguel Arriagada, XII-2015

Poblador ex Campamento Nueva La Habana José Gutiérrez, XII-2015.

Pobladora ex Campamento Nueva La Habana, Irma Mella, III-2016.

Poblador ex Campamento Nueva La Habana, Tomás Ireland, III-2016.

Pobladora ex Campamento Nueva La Habana, Uberlinda Torres, IX-2016.

\section{c) Otros documentos}

Declaración de Principios MIR, 1965, en web del MIR [http://chilemir.tripod.com/ principios.html].

"Posición del MIR: elecciones, no; lucha armada único camino", Documento interno MIR, 1969.

"El MIR y el triunfo de Salvador Allende", Declaración pública, septiembre de 1970, en Archivo Chile, CEME.

"Opinión de un campamento", en Punto Final, 10-X-1970, sección "Correo".

\section{Fuentes secundarias}

\section{a) Artículos}

Alvarado, L., et al. (1973). "Movilización social en torno al problema de la vivienda", en Revista EURE, vol. 3, № 7. Santiago, pp. 37-70.

Castells, M. (1973). "Movimiento de pobladores y lucha de clases en Chile", en EURE (CIDU), Nº7, vol. 3. Santiago, pp. 9-35.

De Ramón, A. (1990). "La población informal. Poblamiento de la periferia de Santiago de Chile 1920-1970", en Revista EURE vol. XVI N50. Santiago, pp. 5-17. Garcés, M. (2015). "El movimiento de pobladores durante la Unidad Popular, 1970-1973", en Atenea, № 512, II semestre, Santiago. 
Garcés, M. (2003). "La revolución de los pobladores, treinta años después", LASA XXIV International Congress, Dallas, Texas, 27-29 de marzo, Panel: "La Revolución Social en el Chile de Allende: treinta años después".

Leiva, S. (2002). "De la toma de terrenos a la toma del poder: el campamento 'Nueva La Habana' y una nueva óptica para la movilización poblacional", Revista de Historia Social y de las Mentalidades, N6, primavera. Santiago, pp. 109-123.

Santa María, I. (1973). "El desarrollo urbano mediante los 'asentamientos espontáneos': el caso de los campamentos chilenos", en Revista EURE, vol. 3, № 7. Santiago, pp. 103-112.

\section{b) Libros y tesis}

Cancino, H. (1988). Chile. La problemática del poder popular en el proceso de la vía chilena al socialismo. 1970-1973. Dinamarca.

Cofré, B. (2007). Historia de los pobladores del campamento Nueva La Habana durante la Unidad Popular (1970-1973). Tesis para optar al grado de Licenciado en Historia y Ciencias Sociales. Santiago: Escuela de Historia y Ciencias Sociales, Facultad de Humanidades, Universidad Arcis.

Espinoza, V (1988). Para una historia de los pobres de la ciudad. Santiago: Ediciones SUR.

Fuentes, F. (2007). Reconstruyendo la historia de Nueva Habana: Una mirada de pobladora, memoria para optar al grado de Licenciado en Historia. Santiago: Departamento de Artes y Humanidades, Facultad de Humanidades y Educación, Universidad Andrés Bello.

Garcés, M. (2014). Tomando su sitio, movimiento de pobladores de Santiago, 1957-1970. Santiago: LOM ediciones.

Hidalgo, R. (2004). La vivienda social en Chile y la construcción del espacio urbano en el Santiago del siglo XX. Santiago. Centro de Investigaciones Barros Arana, DIBAM.

Leiva, S. y Fahra Neghme (2000). La política del Movimiento de Izquierda Revolucionaria (MIR) durante la Unidad Popular y su influencia sobre los obreros y pobladores de Santiago. Tesis para optar al grado de Licenciado en Educación en Historia y Geografía. Santiago: Departamento de Historia, Facultad de Humanidades, Universidad de Santiago de Chile.

Murphy, E. (2015). For a proper home. Housing Rights in the Margins of Urban Chile, 1960-2010. USA: University of Pittsburgh Press.

Palierakl, E. (2014). jLa revolución ya viene! El MIR chileno en los años sesenta. Santiago: LOM. 